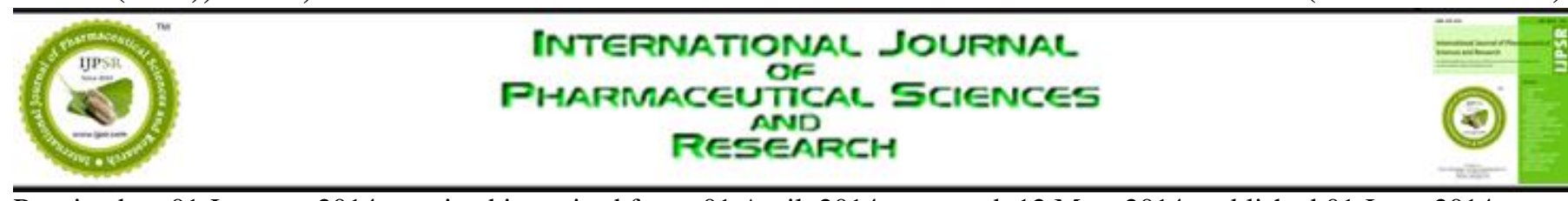

Received on 01 January, 2014; received in revised form, 01 April, 2014; accepted, 12 May, 2014; published 01 June, 2014

\title{
COMPARISON OF BOLUS PHENYLEPHRINE, EPHEDRINE AND MEPHENTERMINE FOR MAINTENANCE OF ARTERIAL PRESSURE DURING SPINAL ANAESTHESIA IN CAESAREAN SECTION
}

Devender Dua, Rashida Jadliwala, Deepa Gondalia, Vandana Parmar* and Ankit Jain

Department of Anaesthesiology, P.D.U Govt. Medical College, Rajkot, Gujarat, India Keywords:

Caesarean Section, Subarachnoid block, Arterial pressure,

Phenylephrine, Ephedrine, Mephentermine

Correspondence to Author:

Dr. Vandana S. Parmar

"Guru-krupa", 4/A, Shardanagar society, University Road, Rajkot. 360005. Gujarat, India

E-mail: drvandanapithadia@yahoo.com

\begin{abstract}
We studied 90 patients undergoing elective as well as emergency caesarean section under spinal anaesthesia who developed hypotension after subarachnoid block (SAB). They were randomly divided in three groups: Group P Phenylephrine $100 \mu \mathrm{g}(\mathrm{n}=30)$, Group E Ephedrine 6mg $(n=30)$ or Group M Mephentermine $6 \mathrm{mg}(\mathrm{n}=30)$ as IV bolus. Hypotension was defined as decrease in systolic arterial pressure > $20 \%$ of baseline values. Elevation of systolic arterial pressure in group $\mathrm{P}$ was significantly high for first 6 min of bolus dose as compared to group $\mathrm{E}$ and $\mathrm{M}$. There was significant reduction in heart rate in group P. Neonatal Apgar score was $>7$ in all three groups.
\end{abstract}

INTRODUCTION: Anaesthesia to parturient is unique but requires highest degree of care. In elective caesarean section under SAB hypotension has been reported in as many as $85 \%$ of patients ${ }^{1}$. Hypotension during SAB for Caesarean delivery can have detrimental effects on mother and neonate, decrease in uteroplacental blood flow, leading to impaired foetal oxygenation with asphyxia stress and foetal acidosis ${ }^{2}$. Various methods for preventing hypotension are left uterine displacement, intravenous fluid preload, trendelenburg position, compression devices on legs, and prophylactic vasopressors. However, no method has proved entirely satisfactory ${ }^{3}$. Despite these conservative measures, vasopressor drug is often required $^{2}$.

\begin{tabular}{|l|c|}
\hline QUICK RESPONSE CODE & DOI: \\
\hline
\end{tabular}

MATERIALS AND METHODS: After approval from institutional ethics committee, 90 parturients ASA I and II, of 20-35 yrs of age scheduled for elective and emergency Caesarean section and who developed hypotension after SAB were included. After informed consent, patients were divided into 3 groups of 30 each:

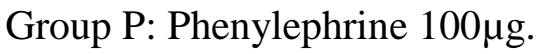

Group E: Ephedrine 6mg

Group M: Mephentermine 6mg

All patients were premedicated with Inj. Glycopyrolate $0.2 \mathrm{mg}$ IV, Inj. Ondansetron $4 \mathrm{mg}$ IV, Inj. Metoclopramide $10 \mathrm{mg}$ IV. Standard monitoring with non-invasive blood pressure, electrocardiography and pulse oximetry was done. Preloading with Ringer's lactate $15 \mathrm{ml} / \mathrm{kg}$ was done. After prehydration, intravenous infusion of lactated ringer's solution was continued at minimal rate to maintain vein patency throughout the study period 
(from induction of spinal anaesthesia till delivery of the baby), without adjustment, regardless of any maternal haemodynamic changes.

Patients were allowed to rest undisturbed in supine position with left uterine displacement for several minutes, during which time blood pressure was monitored every 1 to 2 minutes. When blood pressure measurements became consistent (three successive measurements of systolic blood pressure that had difference of not more than $10 \%$ ), baseline systolic blood pressure and heart rate were taken as mean of three readings.

With patient in left lateral position, $2 \mathrm{ml} 0.5 \%$ bupivacaine heavy was injected intrathecally at L3L4 intervertebral space with 25 gauge spinal needles. Patient was immediately turned supine and 15 degree wedge was placed under right hip to produce left uterine displacement.

Oxygen was administered at rate of $3 \mathrm{~L} / \mathrm{min}$ by face mask until umbilical cord is clamped.

Inj. ergometrine, $0.2 \mathrm{mg}$ slow IV and Inj. oxytocin $20 \mathrm{U}$ in DNS was given after clamping the umbilical cord.

Heart rate and blood pressure were recorded after $\mathrm{SAB}$, then at every $2 \mathrm{~min}$ after onset of hypotension till $20 \mathrm{~min}$ and thereafter every $5 \mathrm{~min}$ till end of surgery.

Whenever hypotension occurs, study drug was given. Number of bolus and time taken to develop hypotension was noted.

Bradycardia (pulse rate of $60 / \mathrm{min}$ or less) was treated with atropine $0.3 \mathrm{mg} \mathrm{IV}$.

Highest level of sensory block was assessed by pinprick method 5 min after SAB.

Induction delivery, incision delivery interval and neonatal apgar score at 1 and 5 minute after delivery were recorded.

Comparability of groups were analysed with Analysis of variance (ANOVA) test. Student's two tailed ' $t$ ' test was applied to analysed parametric data. $\mathrm{P}$ value $<0.05$ was considered significant.
RESULTS: Groups were comparable in demographic profile (Table 1). All three groups were similar in sensory block level, induction delivery and uterine incision - delivery interval and time at which $1^{\text {st }}$ vasopressor dose given.

Systolic and diastolic arterial pressure were decreased statistically significant $(\mathrm{p}<0.001)$ at onset of hypotension and increased after bolus dose of drug in all groups (Table 2 and Table 3 ).

On intergroup comparison rise of systolic blood pressure at 2, 4 and 6 minutes after administration of the vasopressor, mean SBP were significantly less in Ephedrine group and Mephentermine group as compared to the Phenylephrine group [p<0.05] and diastolic blood pressure at 2 and 4 minutes post study drugs were significantly less in Ephedrine group and Mephentermine group as compared to the Phenylephrine group $(\mathrm{p}<0.05)$. No significant differences were observed between changes in systolic and diastolic blood pressure of Ephedrine and Mephentermine group [ $p>0.05]$

At all-time after administration of vasopressors, mean HR was significantly higher in group $\mathrm{E}$ and group $\mathrm{M}$ in comparison to group $\mathrm{P}(\mathrm{p}<0.05)$ (Table 4). Mean $\mathrm{HR}$ was significantly higher in group $\mathrm{E}$ at $2,4,6,8,10$ and 12 minutes in comparison to group $\mathrm{M} \quad(\mathrm{p}<0.05)$. However, no significant differences were observed between group $\mathrm{E}$ and $\mathrm{M}$ [p>0.05]. Mean heart rate raised in all three groups at hypotension compared to baseline value $(p<0.01)$. In group $P$, mean heart rate was significantly less at all time after administration of the vasopressor $(\mathrm{p}<0.01)$ compared to value at time of hypotension. In group E, mean heart rate was statistically non-significant at 2, 4 and 6 minutes compared to that at hypotensive value ( $\mathrm{p}>0.05$ ), with significantly low mean at 8,10 , $12,14,16,18,20,25$ and 30 minutes after administration of the vasopressor compared to that at hypotensive value $(\mathrm{p}<0.05)$. Within group $\mathrm{M}$, mean heart rate was significantly less at all time after administration of the vasopressor $(p<0.01)$ compared to value at time of hypotension.

In group P, $73.3 \%$ patients required single bolus dose while $26.6 \%$ required two doses to maintain systolic pressure within $20 \%$ limit of basal value. 
In group E, $50 \%$ required single, $43.3 \%$ two and $6.7 \%$ three bolus doses. Whereas in group M, 46.7 $\%$ required single, $46.7 \%$ two and $6.7 \%$ three doses. In group $\mathrm{P}, 2$ patients required atropine (heart rate $<60 / \mathrm{min}$ ) while no patient in group $\mathrm{E}$ and $M$ required atropine. Two patients $(6.67 \%)$ in group $\mathrm{P}$ experienced nausea as compared to five $(16.67 \%)$ in group E and seven $(23.33 \%)$ in group M. Two patients $(6.67 \%)$ in group $\mathrm{E}$ had vomiting as compared to three (10\%) in group $\mathrm{M}$ and no patients in group $\mathrm{P}$. The apgar score at 1 and $5 \mathrm{~min}$ were comparable in all groups.

TABLE 1: DEMOGRAPHIC AND RELEVANT DATA

\begin{tabular}{cccc}
\hline & GROUP P & GROUP E & GROUP M \\
& MEAN \pm SD $(\mathbf{n}=\mathbf{3 0})$ & MEAN \pm SD $(\mathbf{n}=\mathbf{3 0})$ & MEAN \pm SD $(\mathbf{n}=\mathbf{3 0})$ \\
\hline Age (years) & $24.27 \pm 3.81$ & $25.77 \pm 3.75$ & $25.73 \pm 3.41$ \\
Height (cm) & $153.33 \pm 6.95$ & $153.40 \pm 5.75$ & $154.47 \pm 4.77$ \\
Weight (kg) & $55.07 \pm 4.98$ & $54.70 \pm 5.40$ & $55.43 \pm 4.98$ \\
Induction-delivery time (min) & $14.17 \pm 2.04$ & $14.37 \pm 1.69$ & $14.33 \pm 1.95$ \\
Uterine incision-delivery time (sec) $_{\text {Time at which 1 }}^{\text {st }}$ vasopressor dose given (min) & $87.83 \pm 11.91$ & $89.47 \pm 10.4$ & $89.6 \pm 13.53$ \\
\hline
\end{tabular}

TABLE 2: CHANGES IN MEAN SYSTOLIC BP (mm Hg)

\begin{tabular}{|c|c|c|c|c|c|c|}
\hline Time & $\begin{array}{c}\text { Group P } \\
\text { Mean } \pm \text { SD }\end{array}$ & $\begin{array}{c}\text { Group E } \\
\text { Mean } \pm \text { SD }\end{array}$ & $\begin{array}{c}\text { Group M } \\
\text { Mean } \pm \text { SD }\end{array}$ & P-E & E-M & P-M \\
\hline Baseline & $127.73 \pm 7.40$ & $130.60 \pm 6.49$ & $130.0 \pm 4.95$ & - & - & - \\
\hline At HP & $* 96.47 \pm 6.27$ & $* 99.67 \pm 6.13$ & $* 99.2 \pm 5.16$ & - & - & - \\
\hline 2 min after V.P. & $* 118.53 \pm 6.72$ & $* 110.33 \pm 6.87$ & $* 108.13 \pm 4.42$ & + & - & + \\
\hline 4 min after. V.P. & $* 120.8 \pm 7.62$ & $* 113 \pm 6.12$ & $* 111.8 \pm 4.62$ & + & - & + \\
\hline 6 min after V.P. & $* 120.67 \pm 10.68$ & $* 113.47 \pm 7.86$ & $* 114.4 \pm 5.81$ & ++ & - & ++ \\
\hline 8 min after V.P. & $* 117.07 \pm 11.36$ & $* 112.93 \pm 7.42$ & $* 115.53 \pm 6.90$ & - & - & - \\
\hline 10 min after VP & $* 115.33 \pm 10.82$ & $* 115.6 \pm 6.53$ & $* 117.87 \pm 6.75$ & - & - & - \\
\hline 12 min after VP & $* 118.13 \pm 7.48$ & $* 117 \pm 6.30$ & $* 119.27 \pm 6.27$ & - & - & - \\
\hline 14 min after VP & $* 120.27 \pm 8.09$ & 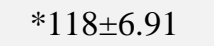 & $* 119.67 \pm 8.26$ & - & - & - \\
\hline 16 min after VP & $* 121 \pm 8.45$ & $* 119.47 \pm 4.75$ & $* 121.53 \pm 5.75$ & - & - & - \\
\hline 18 min after VP & $* 120.47 \pm 7.37$ & $* 120.67 \pm 5.02$ & $* 122.27 \pm 5.53$ & - & - & - \\
\hline 20 min after VP & $* 120.8 \pm 6.80$ & $* 121.33 \pm 5.10$ & $* 122.6 \pm 5.07$ & - & - & - \\
\hline 25 min after VP & $* 123.07 \pm 6.19$ & $* 121.47 \pm 3.82$ & $* 124.4 \pm 6.18$ & - & - & - \\
\hline 30 min after VP & $* 122 \pm 6.12$ & $* 122.07 \pm 3.62$ & $* 124.47 \pm 5.35$ & - & - & - \\
\hline
\end{tabular}

Within the Groups *P $<0.001$, ** $\mathrm{P}<0.05$, \# $\mathrm{P}>0.05$. Between the Groups $+\mathrm{P}<0.001,++\mathrm{P}<0.05,-\mathrm{P}>0.05$. HPHypotension, VP - Vasopressor agents. Within the Groups values were compared between basal and HP values, and HP with post VP

TABLE 3: CHANGES IN MEAN DIASTOLIC BP (mm Hg)

\begin{tabular}{|c|c|c|c|c|c|c|}
\hline TIME & $\begin{array}{c}\text { GROUP P } \\
\text { MEAN } \pm \text { SD }\end{array}$ & $\begin{array}{c}\text { GROUP E } \\
\text { MEAN } \pm \text { SD }\end{array}$ & $\begin{array}{c}\text { GROUP M } \\
\text { MEAN } \pm \text { SD }\end{array}$ & P-E & E-M & P-M \\
\hline Baseline & $83.33 \pm 5.07$ & $81.60 \pm 4.74$ & $81.13 \pm 4.29$ & - & - & - \\
\hline At HP & $* 63.20 \pm 5.57$ & $* 63.13 \pm 6.05$ & $* 63.00 \pm 4.42$ & - & - & - \\
\hline 2 min. after Dr. V.P. Oza & $* 72.53 \pm 5.32$ & $* 68.93 \pm 5.50$ & $* 67.87 \pm 4.16$ & ++ & - & + \\
\hline 4 min after VP & $* 74.73 \pm 5.21$ & $* 69.53 \pm 5.16$ & $* 70.27 \pm 3.96$ & + & - & + \\
\hline 6 min after VP & $* 73.40 \pm 6.77$ & $* 70.73 \pm 4.12$ & $* 72.80 \pm 4.05$ & - & - & - \\
\hline 8 min after VP & $* 74.40 \pm 6.33$ & $* 72.07 \pm 6.86$ & $* 73.93 \pm 6.022$ & - & - & - \\
\hline 10 min after VP & $* 73.47 \pm 8.05$ & $* 74.47 \pm 6.57$ & $* 75.40 \pm 6.44$ & - & - & - \\
\hline 12 min after $\mathrm{VP}$ & $* 75.13 \pm 8.56$ & $* 74.80 \pm 6.61$ & $* 76.20 \pm 5.86$ & - & - & - \\
\hline 14 min after VP & $* 76.73 \pm 7.017$ & $* 76.20 \pm 6.59$ & $* 76.93 \pm 6.14$ & - & - & - \\
\hline 16 min after $\mathrm{VP}$ & $* 76.57 \pm 8.32$ & $* 77.73 \pm 4.89$ & $* 78.60 \pm 5.28$ & - & - & - \\
\hline 18 min after VP & $* 76.93 \pm 7.00$ & $* 78.27 \pm 5.03$ & $* 78.80 \pm 4.83$ & - & - & - \\
\hline 20 min after VP & $* 76.67 \pm 6.57$ & $* 78.87 \pm 5.03$ & $* 78.60 \pm 3.93$ & - & - & - \\
\hline 25 min after VP & $* 77.87 \pm 7.16$ & $* 78.40 \pm 4.83$ & $* 80.27 \pm 4.51$ & - & - & - \\
\hline 30 min after VP & $* 78.73 \pm 7.19$ & $* 79.33 \pm 5.71$ & $* 80.40 \pm 4.43$ & - & - & - \\
\hline
\end{tabular}

Within the Groups *P $<0.001$, ** $\mathrm{P}<0.05$, \# P $>0.05$. Between the Groups $+\mathrm{P}<0.001,++\mathrm{P}<0.05,-\mathrm{P}>0.05$. HPHypotension, VP - Vasopressor agents. Within the Groups values were compared between basal and HP values, and HP with post VP. 
TABLE 4: CHANGES IN MEAN HEART RATE (/MIN)

\begin{tabular}{ccccccc}
\hline Time & $\begin{array}{c}\text { GROUP P } \\
\text { MEAN } \pm \text { SD }\end{array}$ & $\begin{array}{c}\text { GROUP E } \\
\text { MEAN } \pm \text { SD }\end{array}$ & $\begin{array}{c}\text { GROUP M } \\
\text { MEAN } \pm \text { SD }\end{array}$ & P-E & E-M & P-M \\
\hline Baseline & $88.73 \pm 6.39$ & $89.17 \pm 4.19$ & $90.77 \pm 3.72$ & - & - & - \\
HP & $* 101.73 \pm 6.79$ & $* 101.97 \pm 5.02$ & $* 95.37 \pm 5.54$ & - & + & + \\
2 min after VP & $* 81.00 \pm 7.06$ & $\# 102.53 \pm 3.99$ & $* * 94.17 \pm 5.55$ & + & + & + \\
4 min after VP & $* 78.20 \pm 8.93$ & $\# 102.07 \pm 4.45$ & $* 93.23 \pm 7.23$ & + & + & + \\
6 min after VP & $* 82.37 \pm 9.86$ & $\# 100.30 \pm 6.14$ & $* 91.63 \pm 7.41$ & + & + & + \\
8 min after VP & $* 83.83 \pm 9.35$ & $\# 97.97 \pm 7.33$ & $* 90.37 \pm 7.46$ & + & + & + \\
10 min after VP & $* 87.87 \pm 7.70$ & $* * 95.93 \pm 8.85$ & $* 89.33 \pm 6.43$ & + & + & ++ \\
12 min after VP & $* 84.13 \pm 8.88$ & $* 94.10 \pm 9.28$ & $* 88.70 \pm 6.14$ & + & ++ & ++ \\
14 min after VP & $* 81.00 \pm 9.10$ & $* 91.97 \pm 7.49$ & $* 89.63 \pm 5.37$ & + & - & + \\
16 min after VP & $* 79.10 \pm 7.31$ & $* 89.70 \pm 5.19$ & $* 89.30 \pm 4.65$ & + & - & + \\
18 min after VP & $* 79.10 \pm 8.18$ & $* 88.97 \pm 4.45$ & $* 89.73 \pm 4.30$ & + & - & + \\
20 min after VP & $* 78.83 \pm 7.70$ & $* 88.80 \pm 3.93$ & $* 89.87 \pm 3.96$ & + & - & + \\
25 min after VP & $* 79.97 \pm 7.50$ & $* 89.60 \pm 4.24$ & $* 90.20 \pm 3.38$ & + & - & + \\
30 min after VP & $* 80.83 \pm 8.13$ & $* 90.10 \pm 3.73$ & $* 89.074 .46$ & + & - & + \\
\hline
\end{tabular}

Within the Groups *P $<0.001, * * \mathrm{P}<0.05$, \# $\mathrm{P}>0.05$. Between the Groups $+\mathrm{P}<0.001,++\mathrm{P}<0.05,-\mathrm{P}>0.05$. HPHypotension, VP - Vasopressor agents. Within the Groups values were compared between basal and HP values and HP with post VP.

DISCUSSION: After SAB for caesarean section, hypotension can be minimized with fluid, avoidance of aortocaval compression and judicious use of vasopressor agent. We choose percentage changes in systolic blood pressure for treatment of hypotension because percentage decrease in placental perfusion is related to percentage reduction in maternal arterial pressure and not to absolute reduction in pressure ${ }^{4}$. In this study, hypotension was defined as decrease in arterial pressure $>20 \%$ from baseline systolic pressure.

Ephedrine and mephentermine have got mixed action directly as well as indirectly on $\alpha$ and $\beta$ receptors, whereas phenylephrine has pure $\alpha$ receptors activity.

Ganeshanavar et al ${ }^{5}$ reported that rise of systolic and diastolic blood pressure at 2, 4 and 6 minutes post study drugs were significantly less in Ephedrine group and Mephentermine group as compared to Phenylephrine group. No significant differences were observed between changes in systolic, diastolic and mean blood pressure of Ephedrine and Mephentermine group.

Ramanathan et al $^{6}$ reported that $5 \mathrm{mg}$ bolus dose of ephedrine was equipotent to $100 \mu \mathrm{g}$ bolus of phenylephrine.

Thomas and colleagues ${ }^{7}$ reported that bolus phenylephrine $100 \mu \mathrm{g}$ is as effective as ephedrine
$5 \mathrm{mg}$ restoring maternal arterial pressure above $100 \mathrm{mmHg}$.

Recent studies by Simin et $a l^{8}$, Muñoz E et $a l^{9}$ and Nazir et al ${ }^{10}$ also concluded ephedrine and phenylephrine are both effective vasopressores for treatment of hypotension (no significant difference) associated to spinal block during cesarean section without adverse effects on infants/neonates.

Kansal et al ${ }^{11}$ concluded that mephentermine can be used as effectively as ephedrine for the management of hypotension during spinal anaesthesia in patients undergoing elective Caesarean section.

Lee et $a l^{2}$ found that for the management of maternal hypotension, there was no difference between phenylephrine and ephedrine.

Bhattarai $^{12}$ et al also had similar results as our study. Bhardwaj et $\mathrm{al}^{13}$ compared phenylepherine, metaraminol and ephedrine and found all the three vasopressors were equally effective in maintaining maternal blood pressure as well as umbilical $\mathrm{pH}$ without any detrimental effects on fetal and maternal outcome.

In meta-analysis by Lin et al $^{14}$, phenylepherine and ephedrine both were effective in preventing maternal hypotension but phenylephrine was superior to ephedrine in treating hypotension, evidenced by higher umbilical blood $\mathrm{pH}$ values. 
Our results are in disagreement with those reported by Hall and colleagues ${ }^{15}$. They found that number of bolus doses of vasopressor required in phenylephrine group was greater than ephedrine group. This is because they used $20 \mu \mathrm{g}$ bolus of phenylephrine and ephedrine $6 \mathrm{mg}$ as rescue vasopressor. These doses of phenylephrine and ephedrine were not equipotent.

In our study, phenylephrine causes significant reduction in heart rate after bolus dose, which is consistent effect in phenylephrine treated women in other studies $6,7,15$. In spinal anaesthesia, since there is decreased venous return and venous pressure and decreased right heart pressure thus slowing of the heart rate is expected on basis of Bain-bridge reflex. Bradycardia is also expected in high spinal, probably due to some paralysis of cardiac accelerator nerve. Bradycardia could be caused by cardiac sympathetic denervation associated with high spinal block or secondary baroreflex response to vasopressor-induced hypertension.

In current study, there was no difference in extent of anaesthesia achieved. There was no incidence of bradycardia in ephedrine group and mephentermine group. Thus, we conclude that bradycardia was due to reflex decrease in heart rate associated with increase in blood pressure after administration of phenylephrine. However, bradycardia was responsive to atropine treatment without any adverse consequences. We found that maternal heart rate was slower with phenylephrine than with ephedrine and mephentermine because phenylephrine lacks action on beta receptors. This may be advantageous in cardiac patients and patients in whom tachycardia is undesirable.

CONCLUSION: Results of our study suggest that all three vasopressor effectively maintained arterial pressure within $20 \%$ limit of baseline value though phenylephrine maintained better in first $6 \mathrm{~min}$ of bolus dose as compared to ephedrine and mephentermine.

This may be due to that, phenylephrine has peak effect within $1 \mathrm{~min}$, whereas ephedrine has 2-5 min and mephentermine has $5 \mathrm{~min}$.
The apgar score at 1 and 5 min were comparable in all groups.

ACKNOWLEDGEMENT: We are thankful to department of Obstetrics and Gynaecology, P.D.U.M.C., Rajkot and all our patients who are enrolled in study.

\section{REFERENCES:}

1. Riley ET, Cohen SE, Rubenstein AJ, Flanagan B: Prevention of Hypotension After Spinal Anesthesia for Cesarean Section: Six Percent Hetastarch Versus Lactated Ringer's Solution. Anesth Analg 1995; 81: 838-42.

2. Anna L, Warwick D. Ngan K, Tony G: A Quantitative, Systematic Review of Randomized Controlled Trials of Ephedrine versus Phenylephrine for the Management of Hypotension during Spinal Anesthesia for Cesarean Delivery. Anesth Analg 2002; 94:920-6.

3. Kee WD, Khaw KS, Lee BB, Lau TK, Gin T: A doseresponse study of prophylactic intravenous ephedrine for the prevention of hypotension during spinal anesthesia for cesarean delivery. Anesth Analg 2000; 90:1390-5.

4. Corke BC, Datta S, Ostheimer GW, Weiss JB, Alper MH: Spinal anaesthesia for Caesarean section. The influence of hypotension on neonatal outcome; Anaesthesia 1982; 37(6):658-62.

5. Ganeshanavar A, Ambi US, Shettar AE, Koppal R, Ravi R: Comparison of Bolus Phenylephrine, Ephedrine and Mephentermine for Maintenance of Arterial Pressure during Spinal Anaesthesia in Caesarean Section; Journal of Clinical and Diagnostic Research 2011; 5(5):948-52.

6. Ramanathan S, Grant GJ: Vasopressor therapy for hypotension due to epidural anaesthesia for caesarean section; Acta anaesthesiologica Scandinavica 1988;32: 559-65.

7. Thomas DG, Robson SC, Redfern N, Hughes D, Boys RJ: Randomized trial of bolus phenylephrine or ephedrine for maintenance of arterial pressure during spinal anesthesia for Caesarean section. Br J Anaesth 1996; 76(1): 61-65..

8. Simin A, Zahra F, Pouya H, Reza T: Comparison the effect of ephedrine and phenylephrine in treatment of hypotension after spinal anesthesia during cesarean section. Open Journal of Obstetrics and Gynaecology 2012; 2(3):192-6.

9. Alday ME, Palacio AF, De Diego PR, Gilsanz RF: Ephedrine vs. phenylephrine by intravenous bolus and continuous infusion to prevent hypotension secondary to spinal anesthesia during cesarean section: a randomized comparative trial. Rev Esp Anestesiol Reanim 2011; 58(7): 412-6.

10. Nazir I, Bhat MA, Qazi S, Buchh VN, Gurcoo SA: Comparison between phenylephrine and ephedrine in preventing hypotension during spinal anesthesia for cesarean section. Journal of Obstetric Anaesthesia and Critical Care 2012; 2(2):92-7.

11. Kansal A, Mohta M, Sethi AK, Tyagi A, Kumar P: Randomised trial of intravenous infusion of ephedrine or mephentermine for management of hypotension during spinal anaesthesia for Caesarean section; Anaesthesia 2005;60:28-34

12. Bhattarai B, Bhat SY, Upadya M: Comparison of bolus phenylephrine, ephedrine and mephentermine for maintenance of arterial pressure during spinal anesthesia in cesarean section. J Nepal Med Assoc 2010; 49(177):23-8. 
13. Bhardwaj N, Jain K, Arora S, Bharti N: A comparison of three vasopressors for tight control of maternal blood pressure during cesarean section under spinal anesthesia: Effect on maternal and fetal outcome. Journal of Anaesthesiology Clinical Pharmacology 2013; 29(1):2631.

14. Lin FQ, Qiu MT, Ding XX, Fu SK, Li Q: Ephedrine versus phenylephrine for the management of hypotension during spinal anesthesia for cesarean section: an updated metaanalysis. CNS Neurosci Ther 2012; 18(7):591-7.

1. 15. Hall PA, Bennett A, Wilkis MP, Lewis M: Spinal anaesthesia for caesarean section; comparison of infusions of phenylephrine and ephedrine. Br J Anesth 1994; 73: 471-4.

\section{How to cite this article:}

Dua D, Jadliwala R, Gondalia D, Parmar V and Jain A: Comparison of bolus phenylephrine, ephedrine and mephentermine for maintenance of arterial pressure during spinal anaesthesia in caesarean section. Int J Pharm Sci Res 2014; 5(6): 241217.doi: 10.13040/IJPSR.0975-8232.5(6).2412-17

All $\odot 2013$ are reserved by International Journal of Pharmaceutical Sciences and Research. This Journal licensed under a Creative Commons Attribution-NonCommercial-ShareAlike 3.0 Unported License.

This article can be downloaded to ANDROID OS based mobile. Scan QR Code using Code/Bar Scanner from your mobile. (Scanners are available on Google Playstore) 